\title{
Retraction Note to: Conservative Management of Acute Appendicitis
}

\author{
A. A. Malik • S.-u. Bari
}

Published online: 26 October 2011

(C) 2011 The Society for Surgery of the Alimentary Tract

\section{Retraction to: J Gastrointest Surg \\ DOI 10.1007/s11605-009-0835-5}

The editors of the Journal of Gastrointestinal Surgery as well as the SSAT Board of Directors have retracted the article Malik, A.A. \& Bari, S.U. Conservative management of acute appendicitis. J Gastrointest. Surg 13, 966-970 (2009) since significant portions of the article were published earlier in the following articles:

Eriksson,S. \& Granstrom,L. Randomized controlled trial of appendectomy versus antibiotic therapy for acute appendicitis. Br J Surg 82, 166-169 (1995).

Horton,M.D., Counter,S.F., Florence,M.G. \& Hart,M.J. A prospective trial of computed tomography and ultrasonography for diagnosing appendicitis in the atypical patient. Am J Surg 179, 379-381 (2000).

The online version of the original article can be found at http://dx.doi. org/10.1007/s11605-009-0835-5.

\footnotetext{
A. A. Malik $\cdot$ S.-u. Bari $(\bowtie)$

Department of Surgery,

Sher-i-Kashmir Institute of Medical Sciences,

R/o Professors Colony, Naseem Bagh, Hazratbal,

Srinagar, Kashmir 19006, India

e-mail: shamsulbari@rediffmail.com

A. A. Malik

e-mail: ajazamalik@yahoo.com 